\title{
Empathy in the shift to digital
}

\author{
Gwendolyn M. Morel ${ }^{1}$
}

Published online: 11 February 2021

(c) Association for Educational Communications and Technology 2021

\begin{abstract}
Four scholars provide their perspectives in response to Tracey and Hutchinson's (Educ Technol Res Dev 67(5):1259-1272, 2019) article describing the utilization of an empathic design framework. Researchers investigated the association between designers' imagined cognitive and emotional experiences of their learners and the actual learners' representation of the final designed activity.
\end{abstract}

Keywords Empathic design · Instructional design · Shift to digital

Creating meaningful learning experiences was the plight of instructional designers long before any rapid shift to digital learning occurred. However, perhaps in no other time has this unprecedented pivot to remote teaching highlighted the importance of empathy as a key element in designing learning experiences (Koppen and Meinel 2012). According to Tracey and Hutchinson's (2019) article Empathic design: Imagining the cognitive and emotional learning experience, empathic design requires the designer "to predict how the person impacted by the design (in this case the learner) will feel while engaging with the final design solution" (p. 1260). In their article, researchers used an exploratory mixed methods design to investigate the association between designers' imagined cognitive and emotional experiences of their learners and the actual learners' representation of the final designed activity. But what about when the luxury of time to design has been stripped from the process due to unforeseen circumstances? Or even worse, the infrastructure that allows for this kind of thoughtful approach is completely disrupted?

In this shift to digital discussion, Tracey and Hutchinson's (2019) article was chosen to highlight an element in designing learning experiences and the role of empathic forecasting (Pollmann and Finkenauer 2009) in a time of great disruption for students and their learning. Likewise, it seemed possible that revisiting the framework in a period where time and experience to design were primary challenges could be an opportunity to apply the framework in new ways or reconsider it altogether.

In this section, four scholars offer critiques of the original article bringing a range of perspectives. Keahey offers a practical approach where she suggests expanding the application of the framework to teacher training would create some efficiency with design while

Gwendolyn M. Morel

gwendolynmorel@txstate.edu

1 Texas State University, 1702 Ascot Lane, Cedar Park, TX 78613, USA 
increasing teacher self-efficacy (especially in K-12 where teachers are central to instructional delivery). Huh offers a theoretical perspective by providing a discussion about cognitive load theory as it relates to empathic design while also reinforcing the importance of using an iterative approach to improving course quality. From a research perspective, Xie highlights both synchronous and asynchronous delivery modes while also introducing considerations for applying empathic design to learner engagement (i.e. behavioral, cognitive, affective, and social) and learning context (i.e. physical environment, technological, and social features). Mehta and Gleason offer an inclusive perspective aimed at reconsidering empathy as a design approach altogether in favor of humanizing pedagogy to expand the dimensions in which we attempt to understand our learners.

Looking beyond the rapid shift to digital and considering the implications for the longterm benefit of teaching and learning, the pivot to remote delivery seems to have reinforced the need for efficient, yet holistic design approaches that include the emotional response and states of learners as a critical component in their learning experience. Tracey and Hutchinson (2019), our respondents, and others exploring empathic design, humanizing pedagogy, and culturally responsive pedagogy (Lawrence 2020) find meaningful implications for designing inclusive learning experiences. Socioemotional traumatic times paired with the limitations of educational infrastructure creates a reality less than desirable when attempting to perform learner analysis of any type. However, prioritizing elements of holistic design as a regular part of learner analysis and evaluation (Goodyear and Ellis 2008), while expanding the abilities of designers and educators has the potential to increase and maintain connection with learners even if learning situations change.

\section{References}

Goodyear, P., \& Ellis, R. A. (2008). University students' approaches to learning: Rethinking the place of technology. Distance Education, 29(2), 141-152.

Koppen, E., \& Meinel, C. (2012). Knowing people: The empathetic designer. Design Philosophy Papers, $10(1), 35-51$.

Lawrence, A. (2020). Teaching as dialogue: An emerging model of culturally responsive online pedagogy. Journal of Online Learning Research, 6(1), 5-33.

Pollmann, M. M., \& Finkenauer, C. (2009). Empathic forecasting: How do we predict other people's feelings? Cognition and Emotion, 23(5), 978-1001.

Tracey, M. W., \& Hutchinson, A. (2019). Empathic design: Imagining the cognitive and emotional learner experience. Educational Technology Research and Development, 67(5), 1259-1272.

Publisher's Note Springer Nature remains neutral with regard to jurisdictional claims in published maps and institutional affiliations.

Gwendolyn M. Morel is the Director for the Office of Distance and Extended Learning at Texas State University where, in addition to coordinating the administration of self-paced correspondence, extension, and continuing education programs, provides support to Texas State's distance learning programs, courses, initiatives, and resources. 